\title{
Diel and seasonal courses of ambient carbon dioxide concentration and their effect on productivity of the epilithic lichen Lecanora muralis in a temperate, suburban habitat
}

\author{
Otto L. LANGE and T. G. Allan GREEN
}

\begin{abstract}
Ambient $\mathrm{CO}_{2}$ concentration (together with $\mathrm{CO}_{2}$ exchange and microclimate) was recorded every 30 min for 15 months for Lecanora muralis growing in the Botanical Garden Würzburg (Germany, northern Bavaria), a habitat on the outskirts of the city. Annual mean $\mathrm{CO}_{2}$ was around $17 \mathrm{ppm}$ higher than the global average reported for the time of measurement (361 ppm; 1995/96), and daily values ranged from 317 to $490 \mathrm{ppm}$. Diel courses of $\mathrm{CO}_{2}$ could be classified into three different types. Type A, when $\mathrm{CO}_{2}$ levels rose overnight and then fell strongly to below global levels during the day, which predominated in the summer (about $75 \%$ of days); Type B, irregular diel courses occurred during all seasons with often very rapid changes apparently due to advective $\mathrm{CO}_{2}$ transport; Type $\mathrm{C}, \mathrm{CO}_{2}$ concentration was typically almost stable at generally between $c .330$ and $430 \mathrm{ppm}$ which predominated in the winter (63\% of days).

Under controlled conditions, $\mathrm{CO}_{2}$ saturation of net photosynthesis (NP) of L. muralis at optimal hydration and light occurred at around $1000 \mathrm{ppm}$. NP was also affected by low $\mathrm{CO}_{2}$ at limiting light and thallus water contents. Based upon these data, we estimated the improvement of NP of $L$. muralis due to transient increase of ambient $\mathrm{CO}_{2}$ (as compared with the global average) for one selected combination of environmental factors (nocturnal dew or frost). This combination is an important source of water for the lichen, resulting in $40 \%$ of its annual production and, especially in these situations, photosynthesis was increased by high ambient $\mathrm{CO}_{2}$ in the early morning under prevailing Type A conditions. After dew activation, light compensation point of NP occurred at an average concentration of $413 \mathrm{ppm}$ and diel maxima of NP at $402 \mathrm{ppm}$. This allows a rough estimate that the transiently elevated $\mathrm{CO}_{2}$ increased the photosynthetic gain of the lichen after dew of $7 \%$, or an improvement to its annual carbon balance of about $3 \%$. Conditions, especially interrelationships between lichen hydration, light and $\mathrm{CO}_{2}$ are so complex that we are not yet able to extend our estimates to other environmental situations of photosynthetic activity of $L$. muralis.
\end{abstract}

Key words: $\mathrm{CO}_{2}$, dew, global climate change, photosynthesis, water content

\section{Introduction}

The steady increase in global atmospheric $\mathrm{CO}_{2}$ concentration has stimulated interest in its possible effects on the performance of plants. As a result, there is now a wealth of publications dealing with plant behaviour and growth under experimentally increased

O. L. Lange: Julius-von-Sachs-Institut für Biowissenschaften, Universität Würzburg, Julius-von-Sachs-Platz 3, 97082 Würzburg, Germany. Email: ollange@ botanik.uni-wuerzburg.de

T. G. Allan Green: Biological Sciences, University of Waikato, Private Bag 3105, New Zealand.
$\mathrm{CO}_{2}$ concentrations under controlled conditions and in the field (e.g., Ehleringer et al. 2005; Nösberger et al. 2006). The base lines for such studies and, at the same time, for understanding the present situation, are natural time courses of ambient $\mathrm{CO}_{2}$ and their spatial gradients from global to ecosystem and plant levels. Most research efforts concern phanerogamic vegetation and little is known about $\mathrm{CO}_{2}$ as an environmental factor affecting cryptogamic communities, such as lichens and mosses, especially under natural conditions. Some special situations have been investigated where mosses and lichens experience shorter or longer periods of naturally extremely elevated ambient 
$\mathrm{CO}_{2}$. Balaguer et al. (1999) studied acclimation of a lichen to elevated $\mathrm{CO}_{2}$ in the vicinity of a natural $\mathrm{CO}_{2}$ spring. Tarnawski et al. (1992) report an enormous increase in $\mathrm{CO}_{2}$ concentration within and near to the phylloplane of cushion and turf forms of the antarctic moss Grimmia antarctici and this was confirmed by Green et al. (2000) for another antarctic moss, Bryum subrotundifolium. These authors discuss the possible source of carbon dioxide which, most probably, is not moss respiration. Mosses and lichens can benefit when soil respiratory carbon dioxide is trapped within the ground boundary layer. Examples include a subarctic birch forest site (Swedish Lapland; Sonesson 1992), a temperate Nothofagus rainforest (New Zealand; Tarnawski et al. 1994), a temperate podocarp forest (New Zealand; de Lucia et al. 2003) and a subalpine spruce-fir forest (Alberta, Canada; Coxson \& Wilson 2004). Kappen et al. (1995) and Sommerkorn (2000) showed that arctic-alpine lichens benefit from natural $\mathrm{CO}_{2}$ enrichment under a spring snowcover (Swedish Lapland). However, we did not find a single example in the literature of longer-term monitoring of $\mathrm{CO}_{2}$ concentration at an open lichen site.

It is well known that atmospheric $\mathrm{CO}_{2}$ concentration near the ground normally displays distinct seasonal and diel patterns with short-term variations superimposed upon the daily cycle (Geiger et al. 1995). The aim of the present work is to describe the atmospheric $\mathrm{CO}_{2}$ environment for the epilithic lichen, Lecanora muralis (Schreb.) Rabenh., in a long-term study in a suburban, temperate habitat. We then analyse, under controlled conditions, the response of photosynthesis to changes in external $\mathrm{CO}_{2}$, and discuss the possible influence of natural $\mathrm{CO}_{2}$ concentrations on photosynthetic productivity of the lichen taking into account its activity and water status. It must be remembered that these measurements were made more than 10 years ago and, absolute concentrations of global $\mathrm{CO}_{2}$ concentration have since increased. The response patterns that we found will have remained essentially identical.

\section{Measuring site and Methods}

Measurement of atmospheric $\mathrm{CO}_{2}$ concentration (partial pressure, $\mathrm{ppm}$ ) took place during a project in which $\mathrm{CO}_{2}$ exchange, chlorophyll fluorescence, and microclimate conditions for several lichen species were monitored over a period of 2 years and 5 months under quasi-natural conditions in the Botanic Garden Würzburg (Germany, Bavaria, 49 $46^{\prime} \mathrm{N}, 9^{\circ} 56^{\prime} \mathrm{E}$ ).

Lichen photosynthesis and respiration were continually recorded using two automatic cuvette systems (Walz Company, Effeltrich, Germany); the technical details of these 'klapp cuvettes' are described by Lange et al. (1997) and Lange (2002). For the gas exchange measurements, ambient air was continuously taken up from the lichen habitats (flow rate $11 \mathrm{~min}^{-1}$, regulated by mass flow controllers). The placing of the inlet beside the cuvettes $c .5 \mathrm{~cm}$ above the substratum covered by the lichen thalli, ensured that the air used for the measurements was identical to the ambient air experienced by the lichens. During winter snow cover, the air was taken from above the snow. The air stream was divided into a measurement gas stream which passed through the cuvette during $\mathrm{CO}_{2}$ exchange measurements, and a reference gas stream. The absolute $\mathrm{CO}_{2}$ concentration of the latter was measured every 30 minutes by an IRGA (Binos, Rosemount, Hanau, Germany). Before analysis, water content of the air streams (as well as all calibration air streams) was set by a Peltier-operated water vapour condenser. Teflon or steel tubing were used throughout the system. The analyser was calibrated at regular intervals using gas mixtures of known $\mathrm{CO}_{2}$ concentrations (Linde A.G., Germany). Two calibration concentrations were used, one at the lower and one at the upper end of ambient $\mathrm{CO}_{2}$ range both having been checked by means of Wösthoff pumps (see Beyschlag et al. 1986). The same two cylinders were used during the entire measuring period, thus avoiding possible errors through long-term drift of the analyser. Reproducibility of the calibrations was extremely good, and we consider the relative precision of our measurements better than $\pm 1.5 \mathrm{ppm}$ $\mathrm{CO}_{2}$. The absolute error range of the calibration gases is given by the Linde Company as $2 \%$ (i.e. \pm 3.5 to $\pm 5 \mathrm{ppm})$. Loss rate of data was very low. Downloading of data required that monitoring be stopped every four days normally for one reading, and IRGA calibrations caused additional interruptions. Technical problems usually concerned the functioning of the automatic cuvette especially during snow and frost in winter and did not affect recording of the other parameters. Thus, data set loss rate for ambient $\mathrm{CO}_{2}$ was less than the $4 \%$ estimated for the measurements of lichen $\mathrm{CO}_{2}$ exchange (Lange 2003a).

The total data base for all lichens in the study covered the period from March 1995 until August 1997. However, we concentrate here on measurements on the epilithic lichen Lecanora muralis (Schreb.) Rabenh. [syn. Protoparmeliopsis muralis (Schreb.) M.Choisy] made continuously from June 23, 1995 to September 29, 1996, comprising 466 diel courses (see Lange 2002, $2003 a, b)$. We define 'one day' or 'one diel course' as 
always being from 0 to $24 \mathrm{~h}$, and the 'reference year' from July 1995 until June 1996, inclusive, and lying within the 'total measuring period' of 15 months.

The measuring cuvette with the exposed samples of L. muralis was built into a low, $40 \mathrm{~cm}$-high brick wall, covered by sandstone slabs. This installation is described and depicted in detail by Lange (2002). The lichen samples were growing on thin sandstone slices which were included in the cuvette. Measurements were always made on several lichen pieces enclosed together in the cuvette and treated as a single sample. Control experiments have shown that the substratum did not affect $\mathrm{CO}_{2}$ exchange of the lichen thalli. The wall was at an open site in the southern part of the Garden, and was surrounded by other stonewalls, rocks and pavement, all covered for decades with epilithic lichens including L. muralis: a typical situation for a suburban lichen habitat. The Botanic Garden is located on the outskirts of the city of Würzburg (130000 inhabitants), c. $3 \mathrm{~km}$ south of the city centre on an east-facing limestone slope of the Main river valley. To the south-east the Garden is bounded by an elevated four-lane road which is $c .80 \mathrm{~m}$ distant from the measuring site and separated from it by a row of mainly deciduous trees. The Würzburg area represents a relatively dry form of the temperate, central European climate with high sunshine duration $\left(1600 \mathrm{~h}_{\text {year }}{ }^{-1}\right)$, annual mean temperature of $9^{\circ} \mathrm{C}$, and an annual rain fall of c. $600 \mathrm{~mm}$. For detailed information about the weather conditions during the measuring period (Fig. 1) see Lange (2003a), and for the location of the Botanic Garden within its urban surrounding see www.bgw.uni-wuerzburg.de.

The instrumentation for $\mathrm{CO}_{2}$ exchange measurements in the laboratory (Figs. 3, 4, 5) are described by Lange (2002). A 'minicuvette system' was used (Walz Company, Effeltrich, Germany) operating under fully controlled conditions of temperature, light [photosynthetic photon flux density (PPFD) measured over the waveband 400-700 nm], humidity, and external $\mathrm{CO}_{2}$. Factor dependence of $L$. muralis was analysed with samples almost identical to that used for the field measurements, consisting of several sectors of circular thalli growing on thin sandstone slices. Handling of the samples and methodology of the measurements are described in detail by Lange (2002).

\section{Results}

\section{Diel and seasonal courses of ambient $\mathrm{CO}_{2}$ concentration}

At $378 \mathrm{ppm}$ the annual mean ambient $\mathrm{CO}_{2}$ concentration at the lichen site (as calculated from the continuous measurements every $30 \mathrm{~min}$ ) was around $17 \mathrm{ppm}$ higher than the global average reported for the same period of time in 1995/96 (360.74 ppm, Mauna Loa, Hawaii, 3400 m altitude, and $361.5 \mathrm{ppm}$ for the global average over marine surface sites; NOAA ESRL, Global Monitoring Division, www.cmdl. noaa.gov/index.php). The highest diel maximum was $490 \mathrm{ppm}$ (June 1, 1996) and the lowest minimum was $317 \mathrm{ppm}$ (September $25,1995)$ so that the extremes deviated by $+112 \mathrm{ppm}(29 \cdot 6 \%)$ and $-61 \mathrm{ppm}$ $(16 \cdot 1 \%)$, respectively, from the average. The mean weekly minima showed a clear seasonal pattern of lower concentrations in the summer months and higher in the winter (Fig. 1) that reflected the global atmospheric annual changes. In contrast, the weekly maxima seemed to be more the result of special local weather situations: there was no clear annual trend and extreme values occurred during almost every month of the year. The maxima were the result of advective transport from larger sources of $\mathrm{CO}_{2}$ production in combination with specific climatic situations, but we have not been able to correlate these maxima with local events, for example, with changes in automobile traffic.

As is the general rule (Geiger et al. 1995; Buwalda et al. 1992), during the summer the diel course of $\mathrm{CO}_{2}$ concentration was generally enriched with $\mathrm{CO}_{2}$ at night due to $\mathrm{CO}_{2}$ production by soil and plant respiration (Fig. 2, Type A). Increased air stability at reduced wind speed also caused high $\mathrm{CO}_{2}$ at night and this increase was especially marked with strong inversion weather situations. The increase in solar radiation in the morning produced convection and turbulence, and photosynthesis also began, causing a sharp decrease in $\mathrm{CO}_{2}$ concentration. The depression lasted for several hours with $\mathrm{CO}_{2}$ concentrations often remaining lower than $350 \mathrm{ppm} . \mathrm{CO}_{2}$ values increased again at dusk when photosynthesis ceased and air movement was slowed. Large changes in $\mathrm{CO}_{2}$ concentration could occur within a few hours during a single day, the maximal diel differences exceeded $150 \mathrm{ppm}$. The amplitude of such diel variability decreased in late summer and autumn and, in winter, $\mathrm{CO}_{2}$ concentration was typically almost stable at generally between $c .330$ and 430 ppm (Fig. 2, Type C) with only small and irregular 

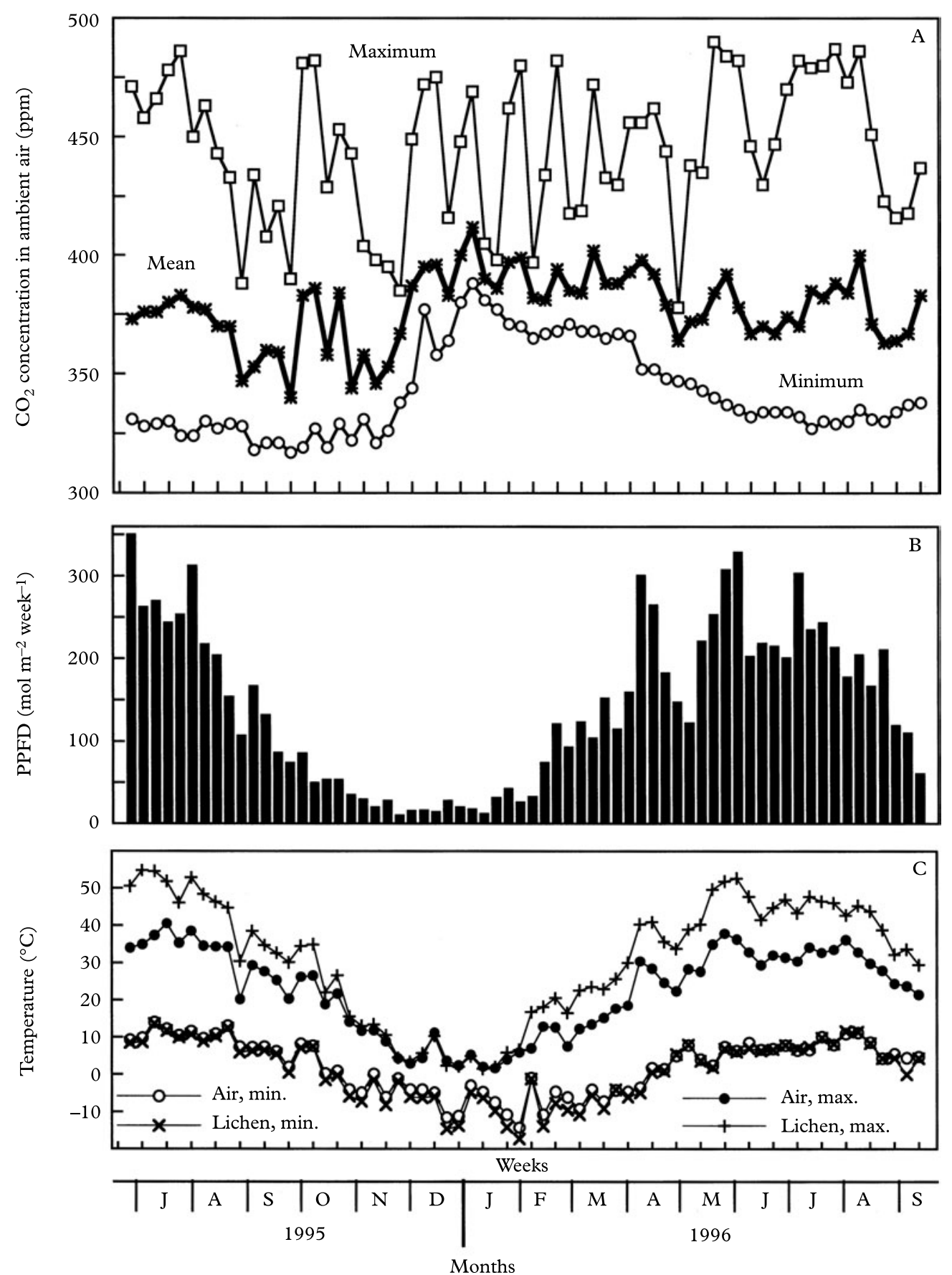

FIG. 1. Ambient $\mathrm{CO}_{2}$ concentration and weather on a weekly basis for the research period July 1995 to September 1996 for Lecanora muralis, Botanical Garden, Würzburg. Abscissa: weeks (every second week marked) and months. A, weekly mean, maximum and minimum of $\mathrm{CO}_{2}$ concentration; $\mathrm{B}$, weekly sum of incident photosynthetically active photon flux density (PPFD); C, weekly maxima and minima of ambient air temperature and of thallus temperature (infrared thermometer). 

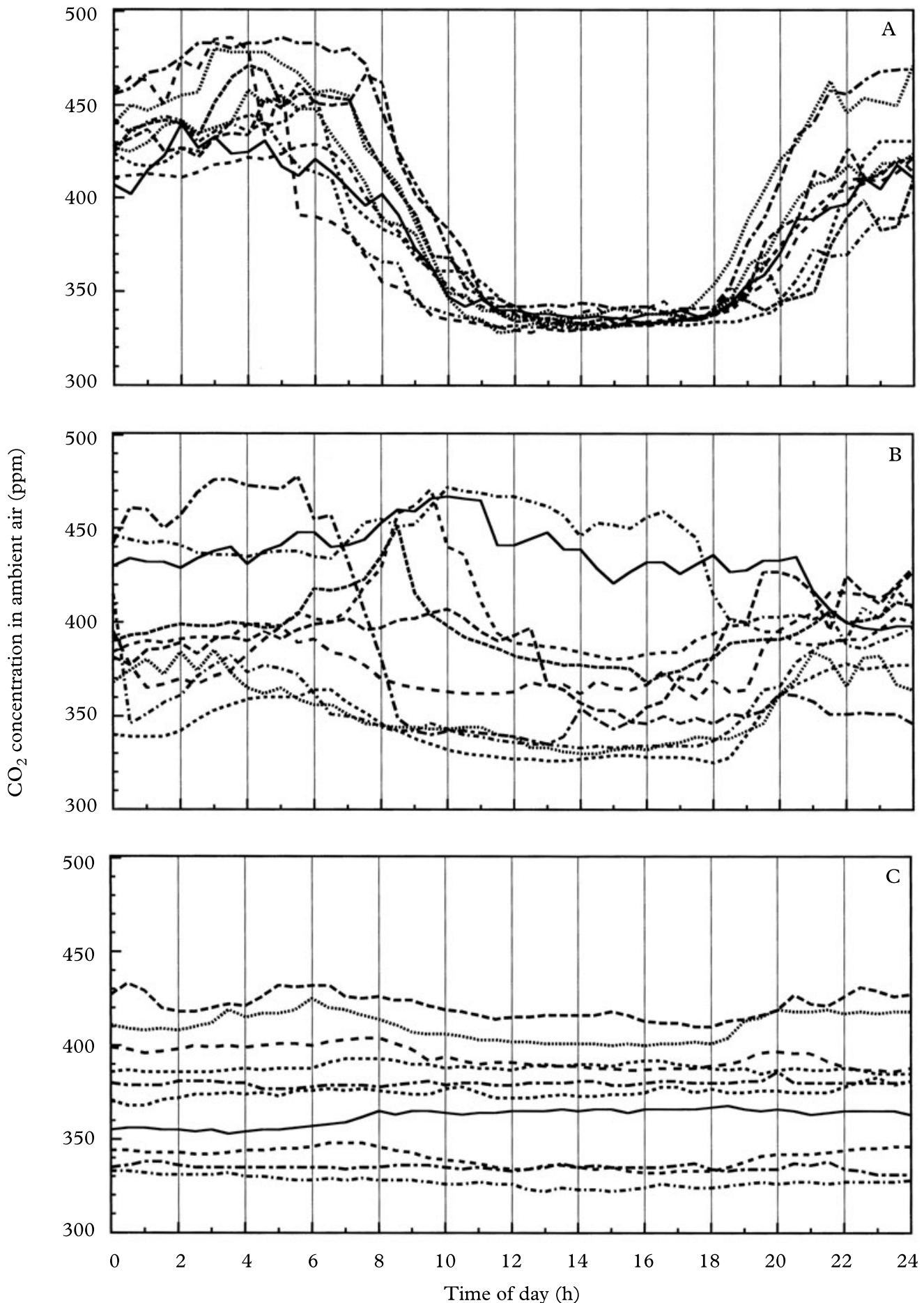

FIG. 2. The three different types (A, B and C) of diel $\mathrm{CO}_{2}$ concentration during the research period for Lecanora muralis, sampling frequency $30 \mathrm{~min}$. A, Type A; B, Type B; C, Type C (see text). 
TABle 1. Percentage of the three types of diel courses of $\mathrm{CO}_{2}$ concentration (see text) during the seasons

\begin{tabular}{|c|c|c|c|}
\hline Season & $\begin{array}{l}\text { Diel course type A } \\
\text { (\% of days) }\end{array}$ & $\begin{array}{c}\text { Diel course type B } \\
\text { (\% of days) }\end{array}$ & $\begin{array}{c}\text { Diel course type C } \\
\text { (\% of days) }\end{array}$ \\
\hline Summer 1995 & & & \\
\hline $\begin{array}{l}\text { (June 23-Sept. 22) } \\
\text { Autumn } 1995\end{array}$ & $79 \cdot 1$ & $16 \cdot 5$ & $4 \cdot 4$ \\
\hline $\begin{array}{l}\text { (Sept. 23-Dec. 20) } \\
\text { Winter 1995/96 }\end{array}$ & $25 \cdot 8$ & $29 \cdot 3$ & $44 \cdot 9$ \\
\hline $\begin{array}{l}\text { (Dec. 21-March 20) } \\
\text { Spring } 1996\end{array}$ & $0 \cdot 0$ & $36 \cdot 7$ & $63 \cdot 3$ \\
\hline $\begin{array}{l}\text { (March 21-June 20) } \\
\text { Summer } 1996\end{array}$ & $53 \cdot 3$ & $23 \cdot 9$ & $22 \cdot 8$ \\
\hline (June 21-Sept. 21) & $72 \cdot 3$ & $23 \cdot 4$ & $4 \cdot 3$ \\
\hline
\end{tabular}

oscillations of around $20 \mathrm{ppm}$. In addition to these regular patterns, irregular diel courses occurred during all seasons with often very rapid changes apparently due to advective $\mathrm{CO}_{2}$ transport (Fig. 2, Type B). They resulted from sudden changes in wind speed for example, during thunderstorms, air pressure changes, heavy rain, or strong changes in solar radiation, and occurred more frequently in winter than in summer. The seasonal distribution of the three types of diel courses in $\mathrm{CO}_{2}$ concentration is given in Table 1. Summer was characterized by a predominance of Type A, and almost $62 \%$ of all winter days belonged to Type C.

\section{Dependence of lichen photosynthesis on external $\mathrm{CO}_{2}$ concentration}

As expected, L. muralis under controlled conditions exhibited a saturation type response curve of net photosynthesis to external $\mathrm{CO}_{2}$ concentration (Fig. 3; Lange 2002). Under saturating light and at optimal thallus water content, $\mathrm{CO}_{2}$ saturation (defined as lowest concentration which allowed $95 \%$ of maximal NP) was at around $1000 \mathrm{ppm} ; \mathrm{CO}_{2}$ compensation point was as low as $16 \mathrm{ppm}$. Minimum (317 ppm) and maximum $(490 \mathrm{ppm})$ natural $\mathrm{CO}_{2}$ concentrations recorded at the site during daylight conditions, produced $56 \%$ and $73 \%$, respectively of maximal NP (under saturating $\mathrm{CO}_{2}$ ). Net photosynthetic carbon uptake at the highest natural $\mathrm{CO}_{2}$ was $c .30 \%$ greater than that at

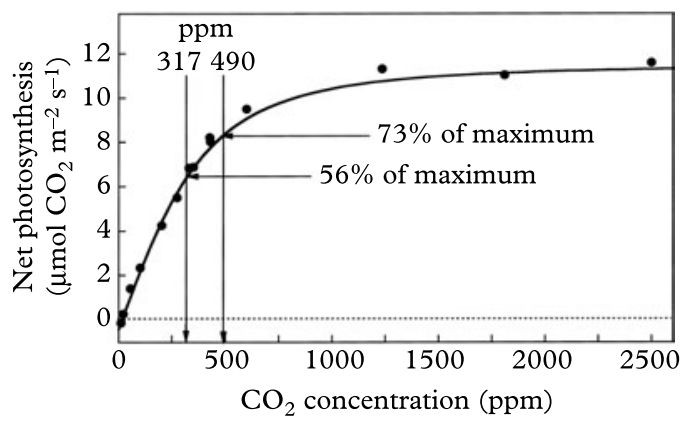

FIG. 3. Net photosynthesis of Lecanora muralis as a function of external $\mathrm{CO}_{2}$ concentration under controlled conditions (optimal thallus water content, saturating light). The numbers 317 and $490 \mathrm{ppm}$ indicate minimum and maximum external $\mathrm{CO}_{2}$ concentration measured under field conditions. The response data (one sample consisting of several thalli, see text) were analysed by fitting of a Smith function, see Smith (1938) and Green et al. (1997):

$$
N P=a \frac{\left[\mathrm{CO}_{2}\right]}{\sqrt{1+\left(\frac{\alpha\left[\mathrm{CO}_{2}\right]}{P M L}\right)^{2}}}-D R
$$

In this equation the dependence of net photosynthesis, $\mathrm{NP}\left(\mu \mathrm{mol} \mathrm{m}{ }^{-2} \mathrm{~s}^{-1}\right)$, at a given dark respiration (DR, $0.421 \mu \mathrm{mol} \mathrm{m} \mathrm{m}^{-2} \mathrm{~s}^{-1}$ ), on carbon dioxide concentration $\left[\mathrm{CO}_{2}\right](\mathrm{ppm})$ is expressed by the parameters $\alpha$, the initial slope of the curve $(0.0262)$, and PML, the maximal rate of $[\mathrm{NP}+\mathrm{DR}](11.9062)$.

the lowest natural concentrations. Typically, the lichen was operating in the field at the beginning of the convex part of its $\mathrm{CO}_{2}$ response curve, that is at the beginning of the transition between the linear response 


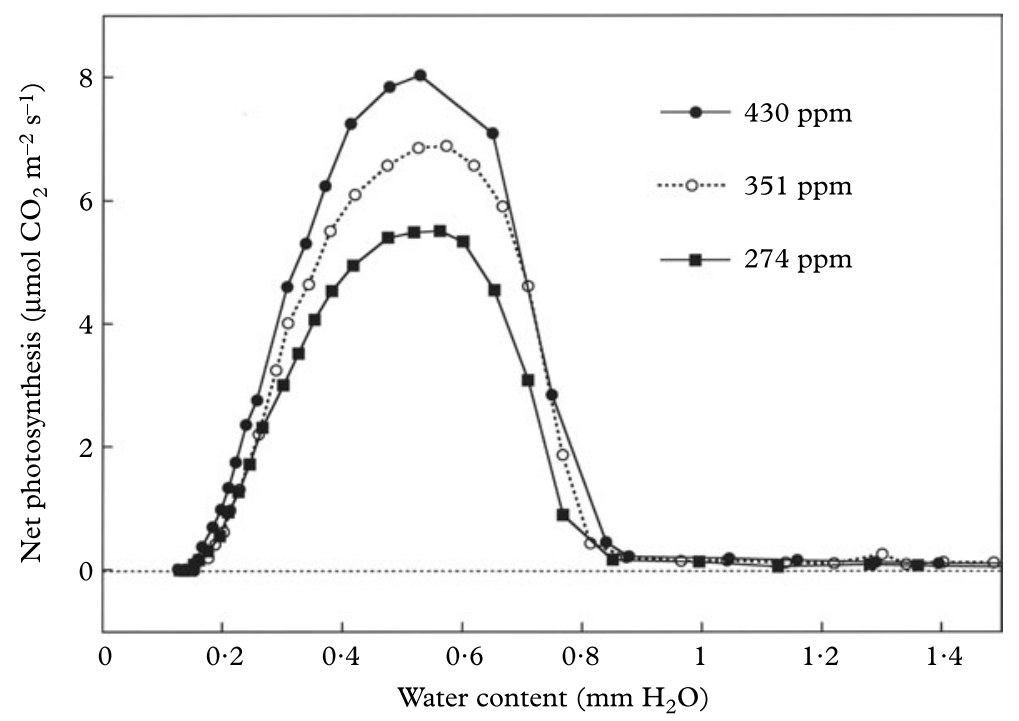

FIG. 4. The dependence of net photosynthesis in Lecanora muralis on thallus water content (mm precipitation equivalent) at three different concentrations of external $\mathrm{CO}_{2}$ and at saturating PPFD (one sample consisting of several thalli, see text).

at low $\mathrm{CO}_{2}$ concentrations and saturated values.

Optimal conditions in terms of water content (WC) and PPFD occurred, at most, only very briefly under natural conditions for the epilithic lichen in a temperate climate. $\mathrm{CO}_{2}$ exchange was usually limited by low hydration or by suprasaturation (Lange $2003 a$ ). Changes in ambient $\mathrm{CO}_{2}$ concentration also affected lichen net photosynthesis at suboptimal thallus water contents. Figure 4 shows drying-down curves of $L$. muralis at three different external $\mathrm{CO}_{2}$ concentrations $(274,351$, and $430 \mathrm{ppm})$. At optimal WC (c. $0.5 \mathrm{~mm}$ precipitation equivalent) the influence of $\mathrm{CO}_{2}$ was similar to that in Fig. 3. The relative reduction in $\mathrm{NP}$ due to decreasing $\mathrm{CO}_{2}$ (after $\mathrm{NP}_{\max }$ ) was initially almost constant at different thallus water contents and remained detectable at very low thallus WC, in some cases close to the moisture compensation point of the lichen. In contrast, changes in external $\mathrm{CO}_{2}$ concentration over the range found in nature had no detectable impact on NP when $\mathrm{CO}_{2}$ uptake was depressed at a WC higher than c. $0.85 \mathrm{~mm}$ (the right portion of the response curves in Fig. 4). Net photosynthesis was reduced almost to zero because thallus diffusion resistance had increased dramatically, restricting $\mathrm{CO}_{2}$ uptake almost completely. We know that much higher concentrations of external $\mathrm{CO}_{2}$ are necessary to overcome this barrier (Lange 2002).

Changes in external $\mathrm{CO}_{2}$ concentration also affected NP at light intensities below light saturation but only at WC lower than that causing suprasaturation. This is shown in Fig. 5 where light response curves of $L$. muralis are depicted for four different ranges of thallus water content and $\mathrm{CO}_{2}$ concentrations of 330 and $430 \mathrm{ppm}$. Differences in $\mathrm{CO}_{2}$ concentration affected NP down to about $100 \mu \mathrm{mol} \mathrm{m}^{-2} \mathrm{~s}^{-1}$ PPFD (the three lowest WC ranges). At still lower light intensities, scatter of measuring points hid differences in this data set. In other experiments with $L$. muralis and with other species we found that larger differences in external $\mathrm{CO}_{2}$ concentration (data not shown) affected the light compensation point of $\mathrm{CO}_{2}$ exchange, confirming earlier findings by Sommerkorn (2000) and by Coxson and Wilson (2004). At thallus suprasaturation (Fig. 5, lowest pair of curves), again, there was no 


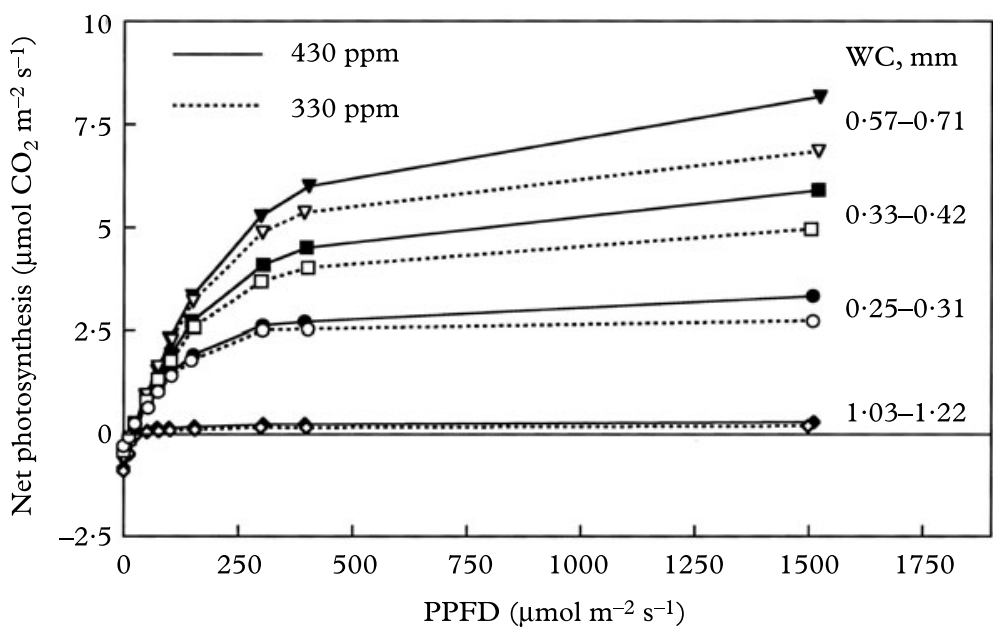

FIG. 5. The dependence of net photosynthesis of Lecanora muralis on incident light (PPFD) for two concentrations of external $\mathrm{CO}_{2}$ at different ranges of thallus water content (WC, precipitation equivalent) (one sample consisting of several thalli, see text).

detectable difference between 330 and 430 external $\mathrm{CO}_{2}$.

\section{Possible significance of external $\mathrm{CO}_{2}$ changes for lichen productivity}

Metabolic activity of lichens is restricted by the occurrence of periods of desiccation. The thin thallus of $L$. muralis had a low water holding capacity and showed high rates of water loss after hydration by dew, fog, rain or high air humidity alone. It was active for only $35.6 \%$ of the total time of the year, made up of $16 \cdot 7 \%$ net photosynthetic $\mathrm{CO}_{2}$ uptake and $18.9 \%$ respiratory $\mathrm{CO}_{2}$ release (Lange 2003a). Only the periods of photosynthesis are influenced by changes in ambient $\mathrm{CO}_{2}$ concentration. We characterized the environmental $\mathrm{CO}_{2}$ conditions on each day when the lichen was photosynthetically active by three values, namely the $\mathrm{CO}_{2}$ concentration: (1) at the time of light compensation during sunrise when the thallus had been hydrated during night or at the beginning of net photosynthesis if hydration took place later during the daylight, (2) at the time of diurnal maximum of $\mathrm{CO}_{2}$ uptake, and (3) at the end of the photosynthetically active period, either, and most commonly, marked by the moisture com- pensation point after desiccation, or by the light compensation point at dusk. The high variability of these values throughout the year means that the averages of these numbers (Table 2) are not statistically different, but they do show characteristic tendencies. The annual mean of daily ambient $\mathrm{CO}_{2}$ concentration at (1), $395 \mathrm{ppm}$, was higher than it was during the daily maximum of net photosynthesis (2), $380 \mathrm{ppm}$, and at the end of the photosynthetically active period (3), $371 \mathrm{ppm}$ (Table 2, upper row). If we assume that the average of these three parameters was the mean $\mathrm{CO}_{2}$ concentration at which L. muralis performed photosynthetic $\mathrm{CO}_{2}$ exchange at its site in the Botanic Garden Würzburg, we arrive at $382 \mathrm{ppm}$, which is $21 \mathrm{ppm}$ higher than the global standard concentration for the same time period.

Days with dew (and fog) or frost are very important for the carbon budget of L. muralis; they contribute $40 \%$ to the total annual carbon balance of the lichen (Lange 2003b). Usually, these periods of photosynthetic activity when the lichen could substantially benefit from increased concentrations of ambient $\mathrm{CO}_{2}$ lasted only for a short period of time after sun rise. Therefore, these situations were especially suited for a more 
TABLE 2. Mean values of ambient $\mathrm{CO}_{2}$ concentration (ppm) at the beginning of positive net photosynthesis (NP) (light or moisture compensation point), at maximum of NP, and at the end of photosynthetic activity when $\mathrm{CO}_{2}$ exchange fell below compensation again, and the average of these three values. Upper row: for all days with metabolic activity of the lichen; lower row: for all days with dew or frost hydration. (Reference year, Fuly 1995 to fune 1996)

\begin{tabular}{lcccc}
\hline & $\begin{array}{c}\mathrm{CO}_{2} \\
\text { at beginning } \\
\text { of positive NP }\end{array}$ & $\begin{array}{c}\mathrm{CO}_{2} \\
\text { at maximum } \\
\text { of positive NP }\end{array}$ & $\begin{array}{c}\mathrm{CO}_{2} \\
\text { at end } \\
\text { of positive NP }\end{array}$ & $\begin{array}{c}\mathrm{CO}_{2} \\
\text { average during } \\
\text { positive activity }\end{array}$ \\
\hline All days of the year & 395 & 380 & 371 & 382 \\
Days with dew activation & 410 & 401 & 384 & 398 \\
\hline
\end{tabular}
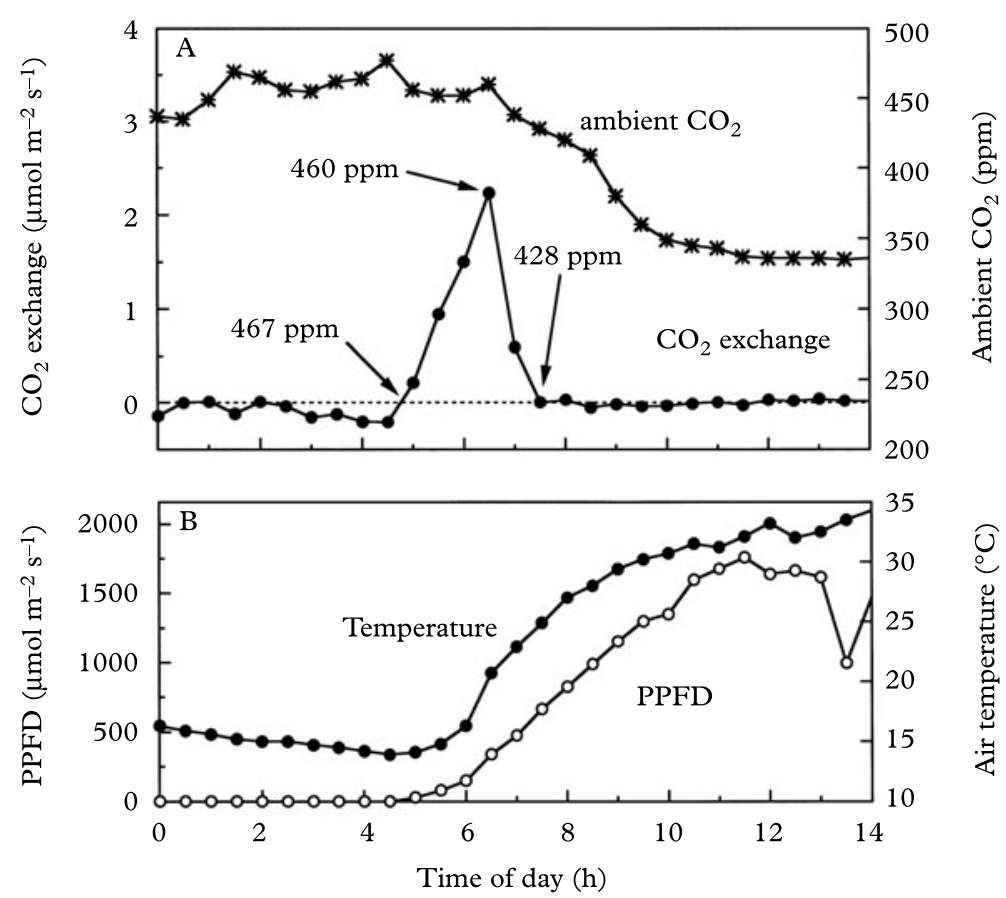

FIg. 6. Time courses for Lecanora muralis on 20 July 1995, Botanical Garden, Würzburg. A, ambient $\mathrm{CO}_{2}$ concentration and area-related $\mathrm{CO}_{2}$ exchange; the $\mathrm{CO}_{2}$ concentrations are indicated for the light compensation point in the morning, maximally achieved net photosynthetic rate, and moisture compensation point after drying; $\mathrm{B}$, incident light (PPFD) and air temperature.

detailed analysis. Nocturnal dew and fog formation usually occurred on nights with high long wave radiation loss and a weather situation with stable air and low turbulence near the ground, that is, during conditions which promote nocturnal $\mathrm{CO}_{2}$ enrichment (Type A situation, Fig. 2). Figure 6 shows an example of a typical lichen performance in summer under such conditions. The thallus became moistened by dew during the night which resulted in low rates of respiration. When the light compensation point was surpassed at 4:45 a.m. (below c. $30 \mu \mathrm{mol} \mathrm{m} \mathrm{m}^{-2} \mathrm{~s}^{-1}$ PPFD) ambient $\mathrm{CO}_{2}$ was $467 \mathrm{ppm}$. It was $460 \mathrm{ppm}$ when maximal NP was reached and had decreased to $428 \mathrm{ppm}$ at the moisture compensation point at 7:30 a.m. when the lichen became dry again. Thus, the average $\mathrm{CO}_{2}$ concentration during its photosynthetic activity at 
that day was c. $452 \mathrm{ppm}$ which is substantially higher than the global annual concentration. During the two summer periods, 1995 and 1996, the lichen experienced 74 days with dew hydration of which 68 days (92\%) showed a Type $\mathrm{A} \mathrm{CO}_{2}$ pattern, only 5 days were Type $B$, and 1 day Type $C$. In Fig. 7 ambient $\mathrm{CO}_{2}$ concentration is shown at light compensation point, maximal NP, and end of the photosynthetic activity for all dew (and frost) events of the total measuring period, with average values of 413,402, and $385 \mathrm{ppm}$, respectively. The respective average values for the reference year are given in Table 2 (lower row).

We can obtain a rough estimate of the increase in net photosynthetic carbon gain of the lichen under the actual ambient $\mathrm{CO}_{2}$ conditions as compared with a $\mathrm{CO}_{2}$ environment of $361 \mathrm{ppm}$, the globally averaged concentration for the years 1995/96 (see above), by looking at selected situations. Restricting the calculation to dew (and frost) hydration and using the regression function depicted in Fig. 3, NP increases from $100 \%$ at $361 \mathrm{ppm}$ to $107 \%$ at $402 \mathrm{ppm}$, the average ambient $\mathrm{CO}_{2}$ during maximal NP after dew moistening. We assume that the lichen would respond similarly to changes in $\mathrm{CO}_{2}$ under the field conditions at maximal NP after dew as it did under optimal water content and saturating light, a view supported by experiments shown in Figs. 4 and 5. If this assumption is accepted, and if we exclude adaptive responses of the lichen photosynthetic and respiratory apparatus (see e.g., Lange \& Green 2005), then average maximal NP after dew under the given environmental conditions will be around $7 \%$ higher than at a level of $361 \mathrm{ppm}$. In the extreme case, at an ambient $\mathrm{CO}_{2}$ concentration of $482 \mathrm{ppm}$, the increase would reach $18 \%$. In Fig. 8, for all dew events with $L$. muralis, diel photosynthetic carbon income showed a strong linear relationship to maximal rate of NP. This means, that increase of ambient $\mathrm{CO}_{2}$ from $361 \mathrm{ppm}$ to an average of $402 \mathrm{ppm}$ for $\mathrm{NP}_{\text {max }}$ would also result in an increase in gross primary production of $7 \%$ which is substantial if one considers that dew and frost hydration provide a large proportion of the total annual carbon budget of the lichen. Interactions between ambient $\mathrm{CO}_{2}$ and carbon income for the other weather response types (see Lange $2003 a, b$ ) such as days with heavy rain or with nocturnal rain and subsequent diurnal drying of the lichen are so complex, that a realistic guess of the impact of ambient $\mathrm{CO}_{2}$ is not yet possible.

\section{Discussion}

The mean $\mathrm{CO}_{2}$ concentrations calculated from measurements directly adjacent to the experimental lichens monitored for over a year (1995/1996) were slightly higher than the accepted global mean of $361 \mathrm{ppm}$. Over the whole year the mean elevation was $17 \mathrm{ppm}$ and, during the period in the early morning when the lichen was physiologically active, about $21 \mathrm{ppm}$. The mean values camouflage some high variability in daily and seasonal patterns during the year. The daily range was substantially higher in the summer, reaching over $180 \mathrm{ppm}$, compared to a much more stable winter value often of around $20 \mathrm{ppm}$. The cause of this change is well known and it reflects the more rapid life processes (photosynthesis and respiration) in the warmer summer. Although the lichen might have had $120 \mathrm{ppm}$ higher $\mathrm{CO}_{2}$ at dawn, it could spend the day many ppm (up to 60 ) below the accepted global value. These values are for a lichen within the ground boundary layer and it is almost certain that they would be different for fruticose or epiphytic species. Other studies have also found elevated $\mathrm{CO}_{2}$ concentrations, in particular when a boundary layer occurs together with a soil respiratory source. Good examples of this would be two studies in forests in New Zealand (Tarnawski et al. 1994; de Lucia et al. 2003). In these two cases the respiratory $\mathrm{CO}_{2}$ was probably generated by tree roots in the soil and it was estimated that the bryophyte soil mat recycled $10 \%$ of the tree respiration (de Lucia et al. 2003). The extreme values are found in two antarctic studies where $\mathrm{CO}_{2}$ concentrations can reach many times the accepted normal values during the day (Tarnawski 

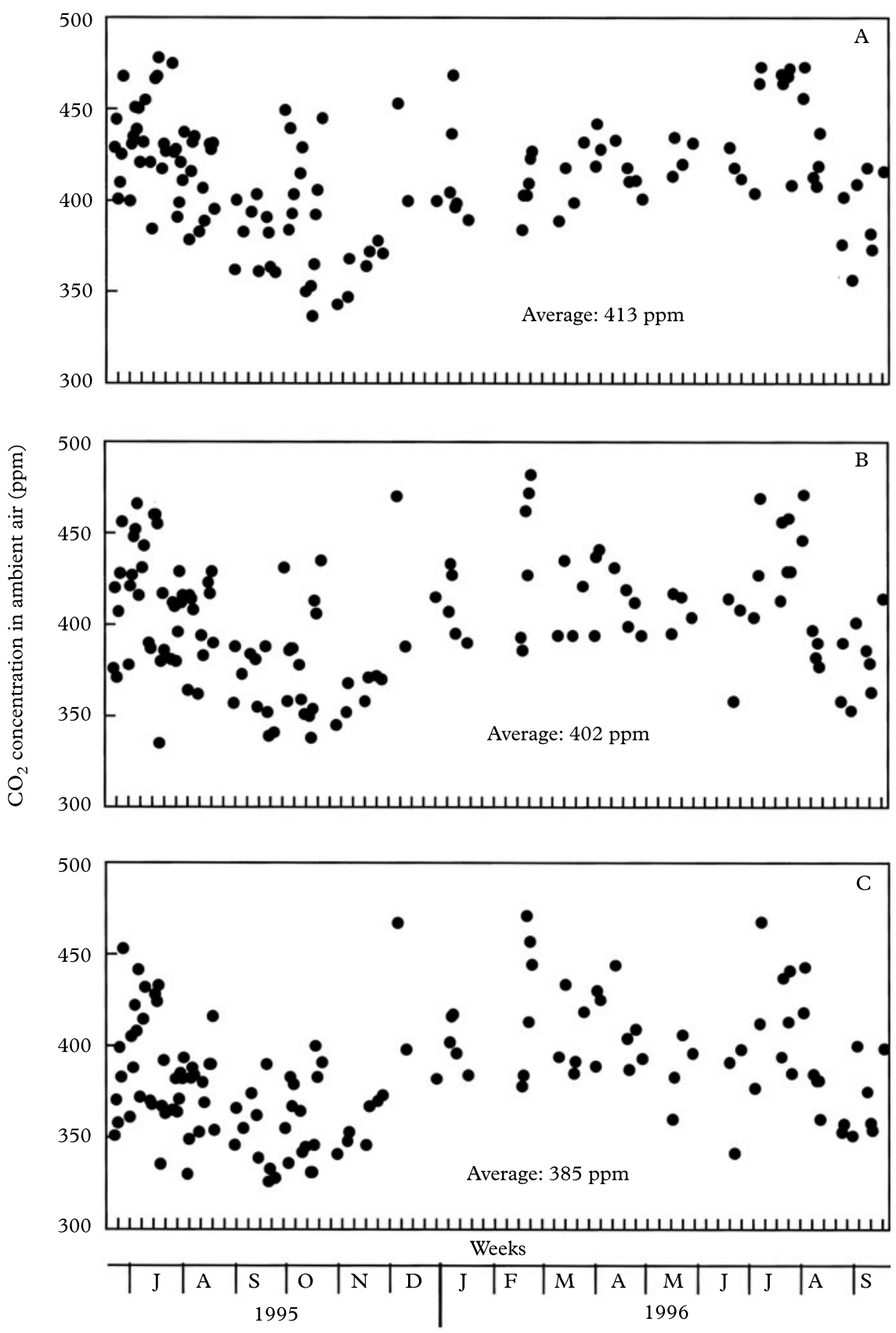

Months of year

FIG. 7. Ambient $\mathrm{CO}_{2}$ concentration for Lecanora muralis on days with metabolic activity initiated by nocturnal moistening with dew (fog) or frost during the measuring period (abscissa, weeks and months). $\mathrm{A}, \mathrm{CO}_{2}$ concentration at light compensation point in the early morning; $\mathrm{B}, \mathrm{CO}_{2}$ concentration at the daily maximum net photosynthetic activity; $\mathrm{C}, \mathrm{CO}_{2}$ concentration at the end of the daily activity (moisture compensation point) when the lichen had become dry again (bottom). In each panel the average $\mathrm{CO}_{2}$ concentration is given for the measurement period. 


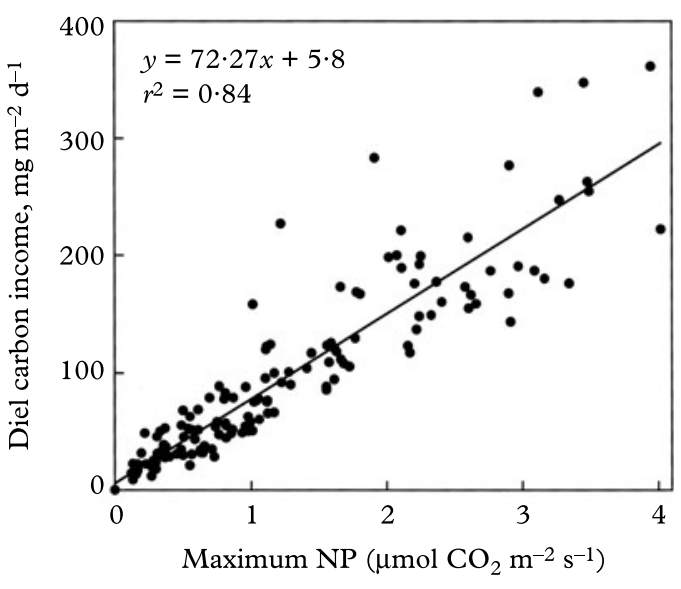

FIG. 8. The relationship between diel net carbon income (integrated net photosynthesis) and maximum rate of net photosynthesis for Lecanora muralis on all days with metabolic activity induced by nocturnal moistening by dew or frost during the measuring period.

et al. 1992; Green et al. 2000). In these cases the source of the $\mathrm{CO}_{2}$ remains a mystery.

It seems, therefore, that the $\mathrm{CO}_{2}$ concentrations around lichens are often different from the global values. The question is, does this situation affect the productivity of the lichens by altering their photosynthetic rate? The lichen studied here, L. muralis, has been extensively researched and its photosynthetic response to $\mathrm{CO}_{2}$ and other environmental factors such as temperature and light, are well known (Lange 2002, 2003a, $b)$. By taking a selected combination of environmental factors, namely the hydration of the lichen by dew or frost in the early morning, it was possible to show that an additional gain of around $7 \%$ in photosynthetic rate occurred due to elevated $\mathrm{CO}_{2}$. The calculation was possible for several reasons: first, we could use the regression line depicted in Fig. 3 as an approximation for NP response to $\mathrm{CO}_{2}$ concentration in the field; second, the WC of the thallus is optimal or suboptimal when hydrated by dew (there is no $\mathrm{CO}_{2}$ enhancement at high WC); and third, the proportional effect of the higher $\mathrm{CO}_{2}$ occurs at all optimal and suboptimal WC and light levels.

It is less easy to estimate gains or losses under other conditions. When the lichen is moistened by extended rain, NP is usually temporarily heavily depressed by high diffusion resistances so that changes in external $\mathrm{CO}_{2}$ concentration have practically no effect on rates of NP. This situation occurs on 74 days, is the most productive in photosynthetic gain but makes almost no contribution to the annual carbon budget $(4 \%)$ because of concomitant high respiration. Two other environmental combinations, wetted overnight and drying during the day, and light showers and continuously wet, make a substantial $35.5 \%$ contribution to the annual carbon gain but, and it is a large but, in these cases most photosynthetic activity occurs during the day when $\mathrm{CO}_{2}$ concentrations are most likely to be decreased below normal global values. At these times the lichens are likely to be losing carbon fixation potential because of the decreased $\mathrm{CO}_{2}$ concentration. However, the data available do not allow a detailed analysis of this complex problem.

To fully quantify the advantage of elevated ambient $\mathrm{CO}_{2}$ for carbon gain in $L$. muralis in its suburban habitat, a model would be necessary which takes into account $\mathrm{CO}_{2}$ dependence of its photosynthesis at different light, temperature and hydration conditions including, for example, $\mathrm{CO}_{2}$ dependence of the light compensation point. However, sufficient data for these complex interrelationships are not available. At best we can say that the hydration by dew contributes $40.0 \%$ of $L$. muralis carbon gain (Lange 2003b) so that we are able to calculate an overall increase of $(7 \cdot 0 \times 0 \cdot 4)$ about $3 \%$ of total lichen carbon gain due to transiently increased external $\mathrm{CO}_{2}$.

We cannot easily extend this to other lichens because not only is the interaction between NP and WC almost species-specific but so, also, is the response of NP to $\mathrm{CO}_{2}$ concentration. Many lichens appear to be saturated at lower $\mathrm{CO}_{2}$ levels than L. muralis. Examples include Flavoparmelia caperata (400 ppm; Balaguer et al. 1999), Sticta latifrons, Pseudocyphellaria billardierii, Peltigera dolichorhiza and Sphaerophorus ramulosum (450 ppm; Green \& Snelgar 1981). These species might be expected to show little or 
no response to changes in ambient $\mathrm{CO}_{2}$ concentrations. However, these responses were all measured under optimal conditions of light and WC and it is known that these optimal combinations are actually very rare (Lange et al. 1993). Certainly, at suboptimal WC we might well expect an improved NP with higher $\mathrm{CO}_{2}$ concentrations.

It is also not so easy to predict what the effects of the present steady increase in global atmospheric $\mathrm{CO}_{2}$ concentrations will be. For L. muralis we can with some confidence say that increases up to around $600 \mathrm{ppm}$ will have an almost linear affect on NP as the lichen is only entering the convex part of its $\mathrm{CO}_{2}$ response curve. At higher levels, the gain will decline as saturation is approached. For other lichens, particularly those with very low $\mathrm{CO}_{2}$ concentrations for saturating $\mathrm{NP}$, we can do little more than guess that, because most lichens operate at non-optimal conditions, there will be a slight increase in carbon gain.

Constructing a model to predict the effects of changes in $\mathrm{CO}_{2}$ concentrations will also be very difficult. The major difference between lichens and higher plants is the poikilohydric nature of lichens which not only means that they spend substantial times desiccated and dormant but also means that there are species-specific differences in water relations and that there is a complex and species-specific interaction between thallus water content and net photosynthesis. As is true for many other lichen carbon fixation problems, the accurate modelling and prediction of thallus water content remains the Holy Grail of lichen ecophysiology.

The research was funded by the Deutsche Forschungsgemeinschaft. Professor M. Riederer is thanked for supporting the work when it continued during the emeritus years of O. L. L. Assistance and help of W. Samfaß, H. Reichenberger, and G. Radermacher with generating, handling and evaluating the data, and of W. Kreßmann with technical support are gratefully acknowledged. Dr U. Buschbom is thanked for his co-operation when the project was conducted in the Botanic Garden Würzburg. T.G.A.G. received assistance from the Alexander-von-Humboldt-Stiftung and the Ramon y Cajal Programme during the research and the preparation of this paper.

\section{REFERENCES}

Balaguer, L., Manrique, E., de los Rios, A., Ascaso, C., Palmqvist, K., Fordham, M. \& Barnes, J. D. (1999) Long-term responses of the green-algal lichen Parmelia caperata to natural $\mathrm{CO}_{2}$ enrichment. Oecologia 119: 166-174.

Beyschlag, W., Lange, O. L. \& Tenhunen, J. D. (1986) Photosynthese und Wasserhaushalt der immergrünen mediterranen Hartlaubpflanze Arbutus unedo L. im Jahreslauf am Freilandstandort in Portugal. I. Tagesläufe von $\mathrm{CO}_{2}-\mathrm{Gaswechsel}$ und Transpiration unter natürlichen Bedingungen. Flora 178: 409-444.

Buwalda, J. G., Green, T. G. A., Meekings, J. S. \& Coneybear, D. J. (1992) Measurement of canopy gas exchange of kiwifruit vines using a suite of whole-canopy cuvettes. Environmental and Experimental Botany 32: 425-438.

Coxson, D. S. \& Wilson, J. A. (2004) Carbon gain in Cladina mitis from mixed feather moss mats in a sub-alpine spruce-fir forest: the role of soil respiratory carbon dioxide release. Symbiosis 37: 307-321.

DeLucia, E. H., Turnbull, M. H., Walcrosft, A. S., Griffin, K. L., Tissue, D. T., Glenny, D., McSeveny, T. M. \& Whitehead, D. (2003) The contribution of bryophytes to the carbon exchange for a temperate rainforest. Global Change Biology 9: $1158-1170$.

Ehleringer, J. R., Cerling, T. E. \& Dearing, M. D. (eds) (2005). A History of Atmospheric $\mathrm{CO}_{2}$ and its Effects on Plants, Animals, and Ecosystems. Ecological Studies 177, New York: Springer.

Geiger, R., Aron, R. H. \& Todhunter, P. (1995). The Climate Near the Ground, 5th edition. Braunschweig Wiesbaden: Vieweg \& Sohn.

Green, T. G. A., Büdel, B., Meyer, A., Zellner, H. \& Lange, O. L. (1997) Temperate rainforest lichens in New Zealand: light response of photosynthesis. New Zealand Fournal of Botany 35: 493-504.

Green, T. G. A., Maseyk, K., Pannewitz, S., Seppelt, R. D. \& Schroeter, B. (2000) Extreme elevated in situ carbon dioxide levels around the moss Bryum subrotundifolium Jaeg., Ber. S. Gall. in Antarctica. Bibliotheca Lichenologica 75: 389-396.

Green, T. G. A. \& Snelgar, W. P. (1981). Carbon dioxide exchange in lichens: relationship between net photosynthetic rate and $\mathrm{CO}_{2}$ concentration. Plant Physiology 68: 199-201.

Kappen, L., Sommerkorn, M. \& Schroeter, B. (1995) Carbon acquisition and water relations of lichens in polar regions - potentials and limitations. $\mathrm{Li}$ chenologist 27: 531-545.

Lange, O. L. (2002) Photosynthetic productivity of the epilithic lichen Lecanora muralis: long-term field monitoring of $\mathrm{CO}_{2}$ exchange and its physiological interpretation. I. Dependence of photosynthesis on water content, light, temperature, and $\mathrm{CO}_{2}$ concentration from laboratory measurements. Flora 197: 233-249.

Lange, O. L. (2003a) Photosynthetic productivity of the epilithic lichen Lecanora muralis: long-term 
field monitoring of $\mathrm{CO}_{2}$ exchange and its physiological interpretation. II. Diel and seasonal patterns of net photosynthesis and respiration. Flora 198: $233-249$.

Lange, O. L. (2003b) Photosynthetic productivity of the epilithic lichen Lecanora muralis: long-term field monitoring of $\mathrm{CO}_{2}$ exchange and its physiological interpretation. III. Diel, seasonal, and annual carbon budgets. Flora 198: 277-292.

Lange, O. L., Büdel, B., Heber, U., Meyer, A., Zellner, H. \& Green, T. G. A. (1993) Temperate rain forest lichens in New Zealand: high thallus water content can severely limit photosynthetic $\mathrm{CO}_{2}$ exchange. Oecologia 95: 303-313.

Lange, O. L. \& Green, T. G. A.(2005) Lichens show that fungi can acclimate their respiration to seasonal changes in temperature. Oecologia 142: 11-19.

Lange, O. L., Reichenberger, H. \& Walz, H. (1997) Continuous monitoring of $\mathrm{CO}_{2}$ exchange of lichens in the field: short-term enclosure with an automatically operating cuvette. Lichenologist 29: 259-274.

Nösberger, J., Long, S. P., Norby, R. J., Stitt, M., Hendrey, G. R. \& Blum H. (eds.) (2006) Managed Ecosystems and $\mathrm{CO}_{2}-$ Case Studies, Processes, and Perspectives. Ecological Studies 187. Berlin: Springer.

Smith, E. L. (1937) The influence of light and carbon dioxide on photosynthesis. Fournal of General Physiology 20: 807-830.

Sommerkorn, M. (2000) The ability of lichens to benefit from natural $\mathrm{CO}_{2}$ enrichment under a spring snow-cover: a study with two arctic-alpine species from contrasting habitats. Bibliotheca Lichenologica 75: 365-380.

Sonesson, M., Gehrke, C. \& Tjus, M. (1992) $\mathrm{CO}_{2}$ environment, microclimate and photosynthetic characteristics of the moss Hylocomium splendens in a subarctic habitat. Oecologia 92: 23-29.

Tarnawski, M., Melick, D., Roser, D., Adamson, E., Adamson, H. \& Seppelt, R. (1992) In situ carbon dioxide levels in cushion and turf forms of Grimmia antarctici at Casey Station, East Antarctica. Fournal of Bryology 17: 241-249.

Tarnawski, M. G., Green, T. G. A., Buedel, B., Meyer, A., Zellner, H. \& Lange, O. L. (1994) Diel changes of atmospheric $\mathrm{CO}_{2}$ concentration within, and above, cryptogam stands in a New Zealand temperate rainforest. New Zealand Fournal of Botany 32: 329-336. 